\title{
Surgical treatment of paediatric postburn contracture of the hand
}

\author{
Alexander J Nicholls*, Yong-June Kim, Vanna Keo and James G Gollogly \\ Children's Surgical Centre, Phnom Penh, Cambodia
}

A 2-year-old girl presented to our institution with a severe volar contracture of the fingers of her right hand secondary to a charcoal cooking-fire contact burn sustained approximately one year prior. Initially treated with simple dressings only, this had resulted in approximately 90-degree proximal interphalangeal joint flexion contractures of all 4 fingers (Figure 1). Her parents had noticed increasing functional impairment as she grew.

Burns are among the leading causes of disability in the developing world [1]. In Cambodia there are over 20,000 incidences of permanent burn disability every year, one third in children under 10 years of age [2] and over $40 \%$ of these involve the hand and upper extremity [1]. There is poor knowledge of burn prevention and first aid, coupled with limited access to adequate treatment, in developing world countries such as Cambodia [3]. These factors all contribute to disabling contracture formation [4].

In this case treatment followed our preferred surgical strategy: careful volar skin release of all 4 fingers preserving neurovascular bundles and flexor sheath where possible, full thickness skin grafting (groin donor site) to the resultant defects and temporary Kirschner wire internal fixation (Figure 2). Wires are removed after 2 to 3 weeks once the skin grafts have taken sufficiently to allow motion and hand therapy.

After approximately 1-year follow-up, although there has been some slight recurrence of contracture (particularly in the more severely affected little finger), a significant improvement in finger extension is seen with full functional flexion possible (Figure 3).

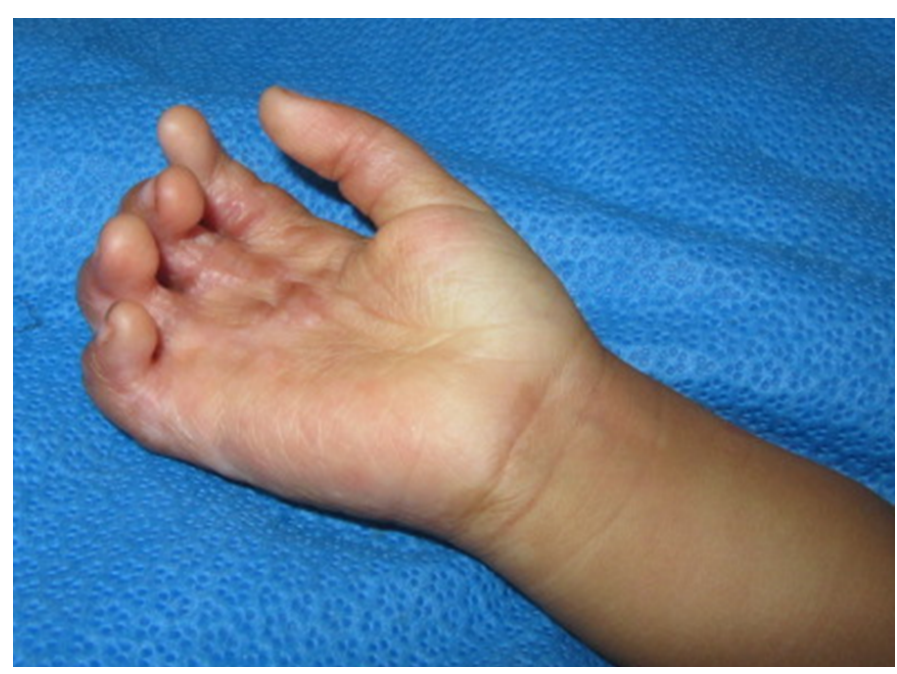

Figure 1. Volar postburn contracture affecting proximal interphalangeal joints of all 4 fingers

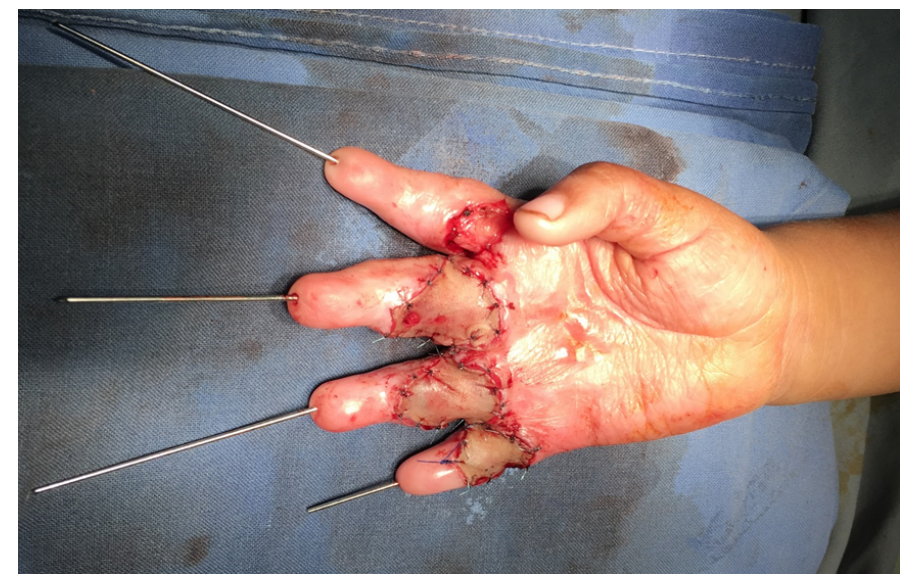

Figure 2. Following skin release and temporary Kirschner wire internal fixation, full thickness skin grafts are performed to the resultant defects

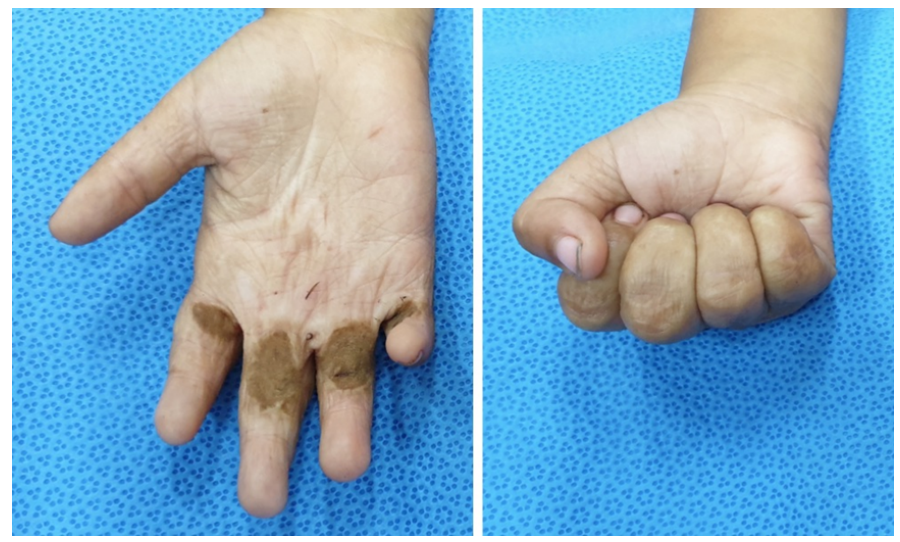

Figure 3. Postoperative flexion and extension at 1-year follow-up

The goal of treatment is to release contracture before permanent secondary deformity develops and thus preserve function [5]. We find that the earlier surgery can be performed, less joint and tendon contractures requiring surgical treatment are seen. Internal fixation with Kirschner wires allows easy wound inspection and care and eliminates the need for splints initially. In our experience the

${ }^{\star}$ Correspondence to: Alexander J Nicholls, Children's Surgical Centre, PO BOX 1060, Phnom Penh, Cambodia, E-mail: alexnicholls@doctors.org.uk

Received: October 20, 2018; Accepted: October 29, 2018; Published: October 31, 2018 
majority of contractures can be treated with skin grafts in this way. Full thickness grafts are preferred to split thickness, being less likely to contract postoperatively [5-7] and the groin donor site morbidity is low [8]. When severe postburn contracture release leads to major tendon and joint exposure, procedures from further up the traditional reconstructive ladder are warranted [7].

\section{References}

1. Borghese L, Latorre S, Montagnese A, De Stefano C (2005) Retrospective analysis of 200 severe post-burn cases in cambodia and bangladesh. Ann Burns Fire Disasters 18 : 5-10. [Crossref]

2. Borghese L, Biancardi F, Gavioli B, Valenti L, Masellis A (2011) Management of a clinical and surgical centre in rural Cambodia (2006-2011). Ann Burns Fire Disasters 24: 186-190. [Crossref]
3. Hsiao M, Tsai B, Uk P, Jo H, Gomez M, et al. (2007) "What do kids know": a survey of 420 Grade 5 students in Cambodia on their knowledge of burn prevention and first-aid treatment. Burns 33: 347-351. [Crossref]

4. Schwarz RJ (2007) Management of postburn contractures of the upper extremity. $J$ Burn Care Res 28: 212-219. [Crossref]

5. Sunil NP, Ahmed F, Jash PK, Gupta M, Suba S (2015) Study on Surgical Management of Post Burn Hand Deformities. J Clin Diagn Res 9: PC06-10. [Crossref]

6. Prasetyono TO, Sadikin PM, Saputra DK (2015) The use of split-thickness versus fullthickness skin graft to resurface volar aspect of pediatric burned hands: A systematic review. Burns 41: 890-906. [Crossref]

7. Fufa DT, Chuang SS, Yang JY (2014) Postburn contractures of the hand. J Hand Surg Am 39: 1869-1876. [Crossref]

8. Kim S, Chung SW, Cha IH (2013) Full thickness skin grafts from the groin: donor site morbidity and graft survival rate from 50 cases. J Korean Assoc Oral Maxillofac Surg 39: 21-26. [Crossref]

Copyright: (C2018 Nicholls AJ. This is an open-access article distributed under the terms of the Creative Commons Attribution License, which permits unrestricted use, distribution, and reproduction in any medium, provided the original author and source are credited. 